\title{
Vasopressin antagonists and dilutional hyponatremia
}

\author{
D Mohamed Babatin MD, Samuel S Lee MD FRCPC
}

\begin{abstract}
ARTICLE
Wong F, Blei AT, Blendis LM, Thuluvath PJ, and the North American VPA Study Group. A vasopressin receptor antagonist (VPA-985) improves serum sodium concentration in patients with hyponatremia: A multicenter, randomized, placebo-controlled trial. Hepatology 2003;37:182-91.
\end{abstract}

"He whose belly swells with dropsy,

The more he drinks, the thirstier he grows" - Ovid, Fasti

\section{COMMENTARY}

The paradox of dilutional hyponatremia, as described by Ovid two millennia ago, continues to apply to patients with advanced cirrhosis today: they have unremitting thirst despite vastly increased total body water. Hyponatremia of less than $130 \mathrm{mmol} / \mathrm{L}$ occurs in $30 \%$ of cirrhotic patients (1), and is mainly due to the reduced capacity of their kidneys to excrete free water.

Several factors may contribute to the development of dilutional hyponatremia in cirrhosis: decreased glomerular filtration rate and, thus, reduced delivery of filtrate to the descending loop of Henle; reduced renal prostaglandin synthesis; and, most importantly, increased nonosmotic secretion of antidiuretic hormone (vasopressin) (2). Vasopressin is synthesized in the neurons of the supraoptic and paraventricular nuclei and released by the neurohypophysis into the systemic circulation. In normal individuals, vasopressin release is suppressed by low plasma osmolality. This feedback regulation is absent in patients with decompensated cirrhosis $(2,3)$; in other words, nonosmotic vasopressin secretion occurs. The two predominant vasopressin receptor subtypes are V1, which is responsible for vasoconstriction in peripheral blood vessels, and V2, which mediates its antidiuretic effects in the kidney.

Vasopressin appears to exert its renal cellular effects via aquaporins. Aquaporin channels are responsible for the transport of water through cell membranes (4). In the luminal membrane of the collecting tubular epithelial cells, vasopressin, acting through the $\mathrm{V} 2$ receptors, stimulates aquaporin-2 receptors to reabsorb free water. By competitively binding to V2 receptors, drugs like VPA-985 antagonize the effect of vasopressin. Aquaporin-2 density increases in cirrhotic rats. Administration of a vasopressin antagonist, however, abolishes aquaporin-2 expression (5).

The traditional management of dilutional hyponatremia is water restriction. However, given the intense thirst, attempts to limit daily water intake to 1000 to $1500 \mathrm{~mL}$ are usually ineffective in the outpatient setting. Moreover, severe water restriction can induce dehydration, further decreasing glomerular filtration rate and renal function, especially in patients with renal impairment or the hepatorenal syndrome.

Accordingly, recent research has examined vasopressin antagonism as a means of increasing free water excretion and thus improving the serum electrolyte profiles. This can be accomplished by either reducing hypothalamic vasopressin production or by blocking renal V2 receptors. Opioid agonists of the $\kappa$-subtype can reduce hypothalamic vasopressin secretion (6) but are of limited use because of their numerous other central nervous systom effects, especially impaired mentation.

This leaves the approach of blocking peripheral V2 receptors in the kidney. Several nonpeptide, orally active VP2 receptor antagonists have been synthesized, of which VPA-985 is the most studied in clinical trials. Prior to the study of Wong and colleagues, the only other clinical study was a small pharmacodynamic dose-finding study in cirrhotic patients with ascites but normal serum electrolytes (7).

The Wong study is important because it was the first phase II study to specifically examine the effects of a V2 antagonist on hyponatremia. This multicenter, randomized, double-blind, placebo-controlled trial involved a total of 44 patients: 33 had cirrhosis, six had congestive heart failure and five had syndrome of inappropriate antidiuretic hormone secretion (8). The patients received various doses of VPA-985 (25 mg twice daily, $125 \mathrm{mg}$ twice daily or $250 \mathrm{mg}$ twice daily) or placebo for a seven-day period, or until correction of hyponatremia. To a certain extent, the eligibility criteria were constructed to reflect clinical practice. For example, patients were allowed to remain on diuretics. Some of the patients had renal impairment; the maximum allowable serum creatinine was $265 \mu \mathrm{mol} / \mathrm{L}$ or less in patients without cirrhosis and $176 \mu \mathrm{mol} / \mathrm{L}$ or less in cirrhotics.

The investigators found that VPA-985 produced a significantly greater aquaretic response than placebo (8). There was a dose-related increase in free water clearance, serum sodium and serum osmolality, and a decrease in urinary osmolality. No 
change in urine sodium excretion was observed. Adverse effects were relatively few, especially at the lower doses. No orthostatic hypotension or change in serum creatinine levels was observed. However, at the highest dosage, patients reported increased thirst, and there were some overt and subtle signs of mild dehydration. Moreover, even in this relatively short-term study, there was evidence of tachyphylaxis. The aquaretic effects appeared to plateau by day 5 , and plasma vasopressin levels continued to rise. Although V2 receptor density was not evaluated in this clinical study, the authors speculated that high vasopressin levels induced the expected receptor downregulation. A similar renal V2-receptor downregulation has been previously noted with high vasopressin levels in dehydration (9). Therefore, the long-term efficacy of these drugs remains unclear.

A few months after Wong et al's study was published, a European multicenter controlled trial of VPA-985 (given for six days) appeared, showing remarkably similar effects (10).

\section{REFERENCES}

1. Arroyo V, Rodes J, Gutierrez-Lizarraga MA, Revert L. Prognostic value of spontaneous hyponatremia in cirrhosis with ascites. Am J Dig Dis 1976;21:249-56.

2. Gines P, Berl T, Bernardi M, et al. Hyponatremia in cirrhosis: From pathogenesis to treatment. Hepatology 1998;28:851-64.

3. Bichet D, Szatalowicz V, Chaimovitz C, Schrier RW. Role of vasopressin in abnormal water excretion in cirrhotic patients. Ann Intern Med 1982;96:413-7.

4. Knepper MA. Molecular physiology of urinary concentrating mechanism: Regulation of aquaporin water channels by vasopressin. Am J Physiol 1997;272:F3-12.

5. Fujita N, Ishikawa SE, Sasaki S, et al. Role of water channel AQP-CD in water retention in SIADH and cirrhotic rats. Am J Physiol 1995;269:F926-31.

6. Lutz-Bucher B, Koch B. Evidence for a direct inhibitory effect of
Further studies obviously need to be done with chronic administration of vasopressin antagonists, and the optimum dosage schedules for various degrees of renal and cardiac dysfunction need to be determined. Moreover, it would be very interesting to see if avidly thirsty patients could eventually drink enough water to overcome the effects of long-term vasopressin antagonism, and 'reset' the serum sodium again at a low level.

In conclusion, treatment of cirrhotic patients with dilutional hyponatremia would be significantly improved by vasopressin receptor antagonists like VPA-985, which improve serum electrolyte levels by increasing renal free water excretion. We are not yet ready to start using these drugs routinely, but this study of Wong and her colleagues is an important first step.

D Mohamed Babatin MD

Samuel S Lee MD FRCPC University of Calgary Liver Unit Calgary, Alberta

morphine on the secretion of posterior pituitary hormones. Eur J Pharmacol 1980;66:375-8.

7. Guyader D, Patat A, Ellis-Grosse EJ, Orczyk GP. Pharmacodynamic effects of a nonpeptide antidiuretic hormone $\mathrm{V} 2$ antagonist in cirrhotic patients with ascites. Hepatology 2002;36:1197-205.

8. Wong F, Blei AT, Blendis L, Thuluvath P. A vasopressin receptor antagonist (VPA-985) improves serum sodium concentration in patients with hyponatremia: A multicenter, randomized, placebocontrolled trial. Hepatology 2003;37:182-91.

9. Steiner M, Phillips MI. Renal tubular vasopressin receptors downregulated by dehydration. Am J Physiol 1988;254:C404-10.

10. Gerbes AL, Gulberg V, Gines P, et al. Therapy of hyponatremia in cirrhosis with a vasopressin receptor antagonist: A randomized double-blind multicenter trial. Gastroenterology 2003;124:933-9. 


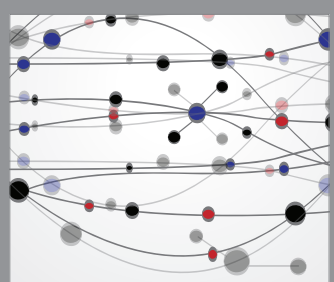

The Scientific World Journal
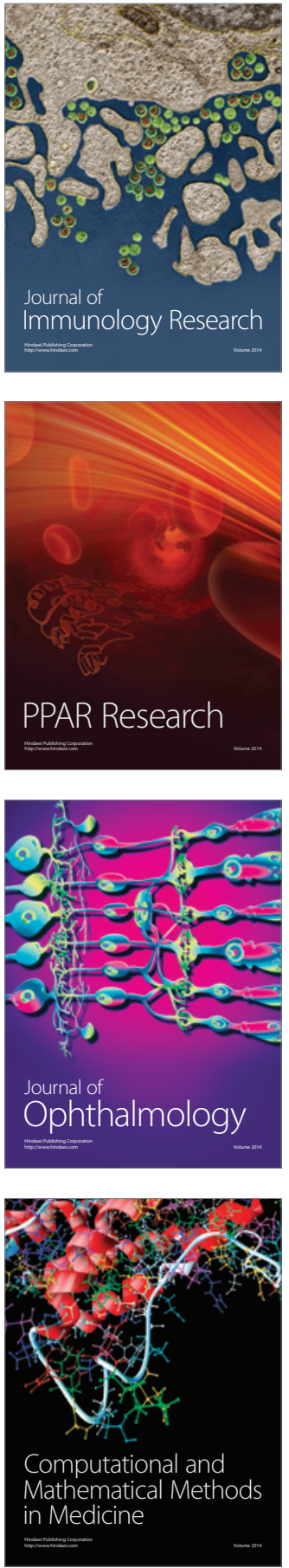

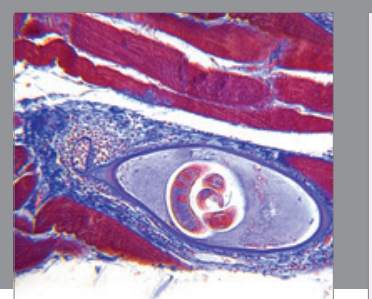

Gastroenterology Research and Practice

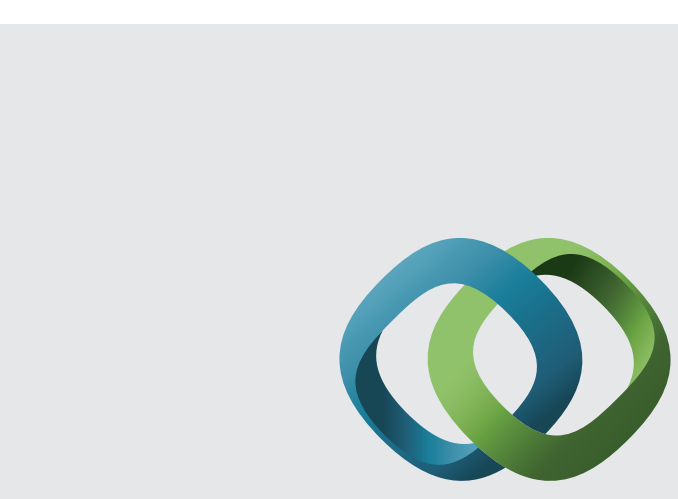

\section{Hindawi}

Submit your manuscripts at

http://www.hindawi.com
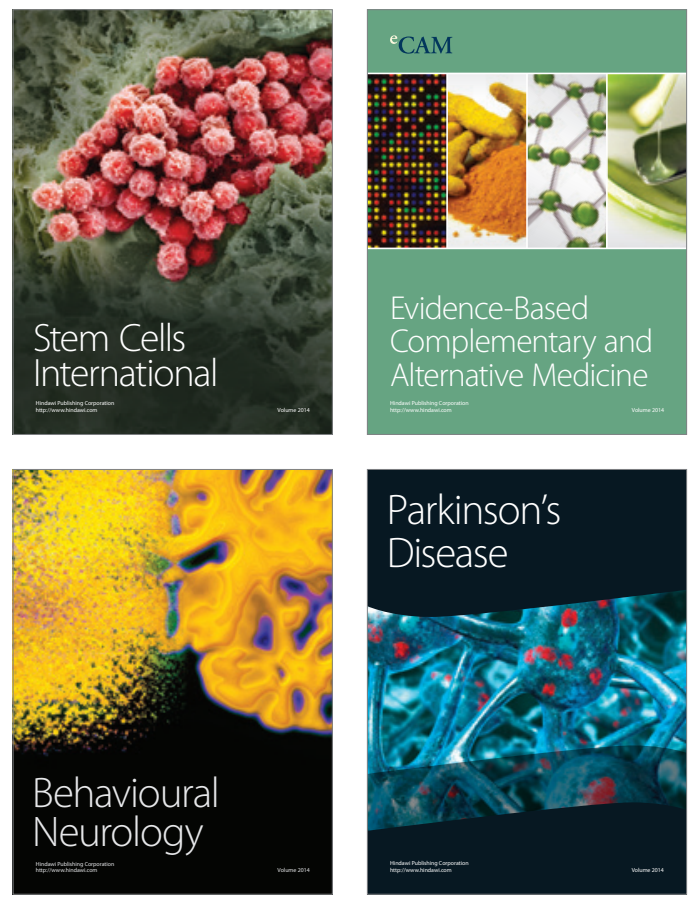
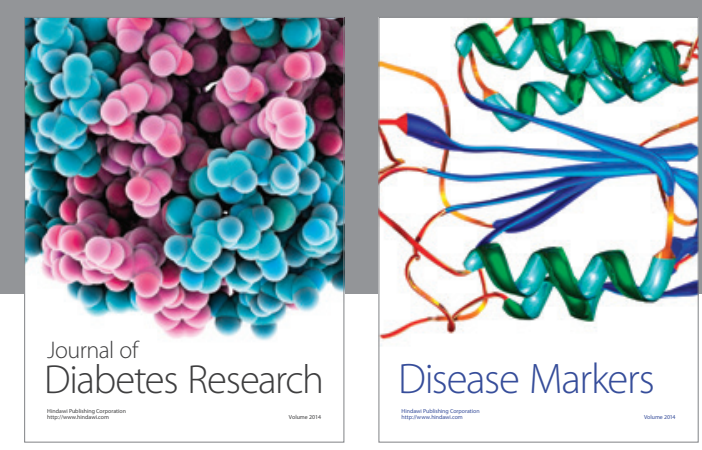

Disease Markers
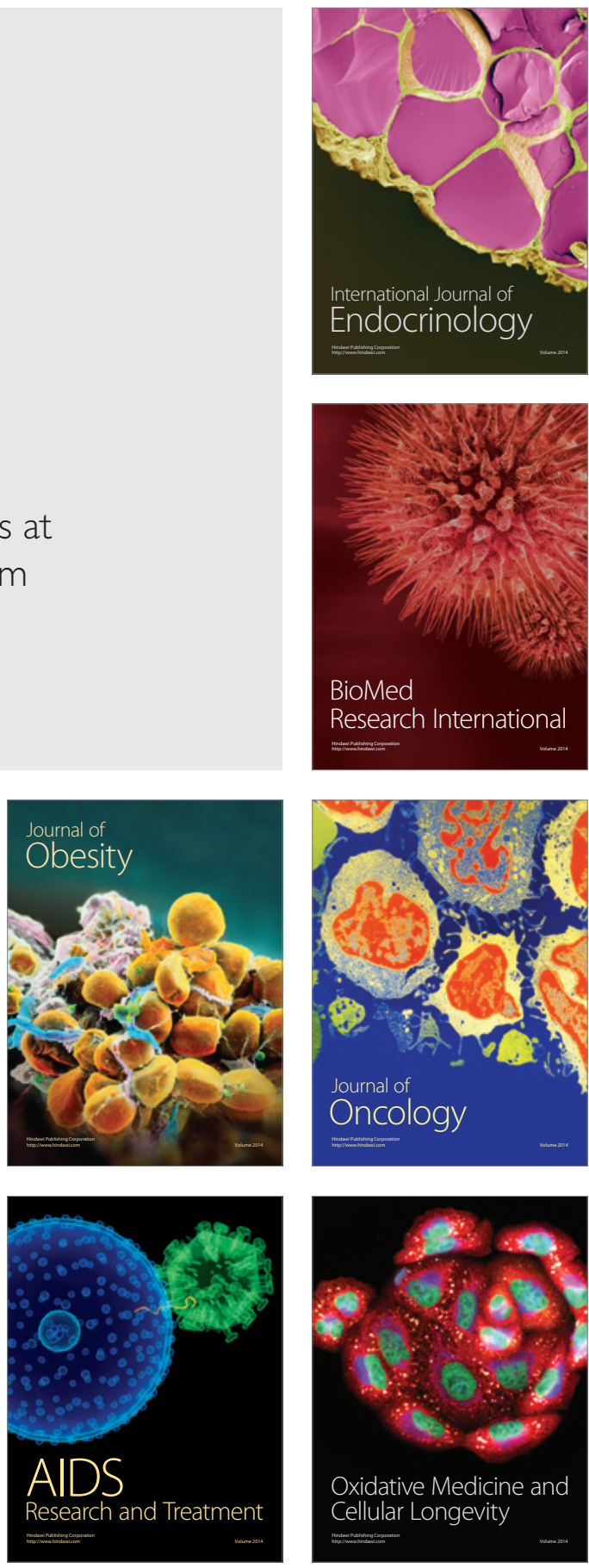